\title{
The Risk of Subsequent Deep Vein Thrombosis and Pulmonary Embolism in Patients with Nontyphoidal Salmonellosis: A Nationwide Cohort Study
}

\author{
Renin Chang ${ }^{1,2,3}$, Den-Ko Wu ${ }^{1,2}$, James Cheng-Chung Wei ${ }^{4,5,6}$, Hei-Tung Yip ${ }^{7}$, \\ Yao-Min Hung $8,9,10, *$ and Chih-Hsin Hung $1, *$ \\ 1 Institute of Biotechnology and Chemical Engineering, I-Shou University, Kaohsiung 840, Taiwan; \\ rhapsody1881@gmail.com (R.C.); dkw3275@gmail.com (D.-K.W.) \\ 2 Department of Emergency Medicine, Kaohsiung Veterans General Hospital, Kaohsiung 813, Taiwan \\ 3 Department of Recreation Sports Management, Tajen University, Pingtung 90741, Taiwan \\ 4 Division of Allergy, Immunology and Rheumatology, Chung Shan Medical University Hospital, \\ Taichung 402, Taiwan; wei3228@gmail.com \\ 5 Institute of Medicine, Chung Shan Medical University, Taichung 402, Taiwan \\ 6 Graduate Institute of Integrated Medicine, China Medical University, Taichung 404, Taiwan \\ 7 Management Office for Health Data, China Medical University Hospital, Taichung 404, Taiwan; \\ fionyip0i0@gmail.com \\ 8 Department of Internal Medicine, Kaohsiung Municipal United Hospital, Kaohsiung 804, Taiwan \\ 9 School of Medicine, National Yang Ming University, Taipei 112, Taiwan \\ 10 Yuh-Ing Junior College of Health Care and Management, Kaohsiung 807, Taiwan \\ * Correspondence: ymhung1@gmail.com (Y.-M.H.); chhung@isu.edu.tw (C.-H.H.); \\ Tel.: +886-7-555-2565 (Y.-M.H.); +886-76577711-3414 (C.-H.H.)
}

Received: 18 March 2020; Accepted: 18 May 2020; Published: 19 May 2020

check for updates

\begin{abstract}
The purpose of this study was to evaluate the deep vein thrombosis (DVT) and pulmonary embolism (PE) risk among patients with a diagnosis of nontyphoidal salmonellosis (NTS) in an Asian population. The risk was analyzed in a cohort of 17,855 patients newly diagnosed with NTS and 71,420 individuals without NTS using a hospitalization claim dataset. Both groups were matched by age, sex, and index date as an original analysis. A Cox proportional-hazards regression model was applied to estimate the risk of DVT and PE, accounting for any competing event (death). With a follow-up of $4.94( \pm 3.93)$ years in the NTS group and $6.30( \pm 3.67)$ years in the non-NTS group, the adjusted subhazard ratios (SHRs) of DVT and PE were 1.83 (95\% CI 1.44-2.31) and 1.84 (95\% CI 1.30-2.60). The NTS group had an increased risk of DVT and PE compared with the control group in all of the age subgroups. Stratified analyses showed that patients aged 18-39 years in the NTS group had significantly higher DVT and PE risks compared with patients of the same age in the non-NTS group (aHR, 5.95; 95\% CI, 2.22-15.91 for DVT; aHR 6.72; 95\% CI, 2.23-20.30 for PE). The $P$-value for interaction between age and exposure of NTS is $<0.001$ for DVT and 0.004 for PE in our sub-group analyses. The findings were cross-validated by a re-analysis with propensity score matching (PSM), and that revealed consistent results. Despite of low absolute risk, clinicians should be aware that patients with an NTS hospitalization history is at increased risk for VTE especially when assessing patients coincident with other VTE risk factors.
\end{abstract}

Keywords: nontyphoidal salmonellosis; venous thromboembolism; deep vein thrombosis; pulmonary embolism; cohort study 


\section{Introduction}

Salmonellae is one of the leading global causes of diarrheal diseases and responsible for a substantial burden of food-borne illnesses. Salmonellae, able to survive weeks in a dry environment, and months in water, are motile Gram-negative intracellular bacteria with bewildering array of clinical characteristics, from uncomplicated gastroenteritis to focal metastatic infections. Nontyphoidal salmonellosis (NTS) is characterized by acute onset of fever, abdominal pain, and diarrhea. Symptoms can be severe in the young, the elderly, and patients with multiple co-morbidities and weakened immunity. Venous thromboembolism (VTE) is a collective term that includes deep vein thrombosis (DVT) and pulmonary embolism (PE), which can be fatal [1]. PE is one of the foremost causes of cardiovascular mortality, overtaken only by stroke and acute myocardial infarction [2]. The interplay between Salmonellae and the development of thrombosis has been known for more than a century, and subsequent studies have confirmed that acute infections are a risk factor for subsequent VTE [3-8]. Several animal models have shown the impact of bacterial infections on subsequent inflammation and coagulation in vivo. In contrast to other pathogens, such as Staphyloccocus aureus, Klebsiella pneumoniae, and Pseudomonas aeruginosa, where the hosts' responses including increased platelet aggregation can last from minutes to hours, Salmonella typhimurium appears to initiate infection-driven thrombosis by an alternative pathway with increased platelet aggregation, for example in the liver vasculature, lasting for several weeks [9]. In another recent study using mouse bone marrow-derived macrophages infected with Salmonella typhimurium, it was demonstrated that, even when restricted in the macrophages, some NTS can secret effectors by the Salmonella pathogenicity island 2 type III secretion system to induce macrophage polarization from pro-inflammatory innate immune responses to anti-inflammation and thus undermine the host's immune defense and survive for extended periods [10]. Based on these studies of pathogen-induced thrombosis and bacterial persistence in animal models, we hypothesized that patients with NTS have an increased risk of VTE for a prolonged period following their acute infection. However, there is little epidemiologic evidence to support this hypothesis. Thus, we performed a nationwide population-based cohort study to analyze the risk of VTE in people with a history of NTS.

\section{Materials and Methods}

\subsection{Data Source and Study Design}

This study was approved by the Research Ethics Committee of China Medical University and Hospital in Taiwan (CMUH-104-REC2-115). Because the study applied de-identified the secondary dataset, released for research purposes, the need for informed consent was waived.

NHIRD contains health care data of more than $99 \%$ of the 23.6 million residents in Taiwan since 1995. All medical claims were sent to the Bureau of National Health Insurance (NHI) for validation and reimbursement. The registration files included demographics, all types of medical visits, and prescriptions codes; before 2016, the procedure and diagnostic codes were based on the International Classification of Diseases, 9th Revision, Clinical Modification (ICD-9-CM). To ensure the accuracy of disease diagnosis, the Bureau of NHI randomly reviewed the medical charts of one in 20 inpatient claims. Based on the original claim data in Taiwanese National Health Insurance Research Database (NHIRD), several specific data subsets are constructed for research purposes. We conducted a population-based cohort study by retrieving the inpatient dataset, a subset from NHIRD, including the original claim data of inpatients by admission.

\subsection{Study Population}

All adult patients aged 20 years or older with a first-time discharge diagnosis of NTS in the period from January 2000 to December 2013 were identified within the inpatient dataset. NTS diagnosis was defined as a discharge diagnosis using the ICD-9-CM code 003.XX. Administrative coding for NTS has been applied in a previous study [11]. The index date was defined as the NTS diagnosis date. Patients 
were excluded if they were younger than 20 years of age, had a history of NTS or VTE before their entry into the study, or died during hospitalization for NTS. To avoid selection bias, the control group (no history of NTS) was randomly selected by computer from the database. The control individuals were matched according to sex, age, and index dates. Index dates for subjects in the control group were randomly assigned and corresponded to individuals in the NTS group. Both groups fit the same inclusion and exclusion criteria. In the primary analysis, both cohorts were individually matched at a ratio of 1:4 by sex, gender, and index date. We re-analyzed the data by propensity score matching to test the robustness of the study findings.

\subsection{Outcome and Relevant Variables}

The main outcome was the diagnosis of VTE during the follow-up period. All patients were followed until the occurrence of VTE, until withdrawal from health insurance, or until 31 December, 2013. To mitigate the effects of potential confounders, we included the following covariates on the dataset for analysis: age, gender, and relevant medical co-morbidities for the development of VTE, including diabetes mellitus (ICD-9-CM code 250), hypertension (ICD-9-CM codes 401-405), hyperlipidemia (ICD-9-CM code 272), chronic obstructive pulmonary disease (ICD-9-CM codes 491, 492, 496), asthma (ICD-9-CM code 493), coronary artery disease (ICD-9-CM codes 410-414), stroke (ICD-9-CM codes 430-438), chronic kidney disease (ICD-9-CM code 585), cancer (ICD-9-CM codes 140-208), sleep apnea (ICD-9-CM codes 327.23, 780.51, 780.53, 780.57), rheumatoid arthritis (ICD-9-CM code 714), atrial fibrillation (ICD-9-CM code 427.31), chronic liver diseases (ICD-9-CM code 571.4), pregnancy (ICD-9-CM codes 640.x1-676.x1, 640.x2-676.x2, 650-659 and with procedure codes 72-74), and lower limb fracture or surgery (ICD-9-CM codes 820-823 and with procedure codes 81.51, 81.52, 81.53 , and 81.54 ). Information was obtained by tracing all the inpatient records in the NHI database within 2 years before the index date.

\subsection{Statistical Analysis}

For analysis of general characteristics of the individuals in the both cohorts, categorical and continuous variables were analyzed using chi-square and Student $t$-tests, respectively. We defined person-years by calculating the sum of the follow-up period for each individual. The individual follow-up period was obtained from the index date to the occurrence of VTE, withdrawal from the NHI program (for examples, people missing over 6 months, emigration, in prison, or death), or the end of 2013-whichever occurred first. The incidence rate was calculated according to the number of occurrences and person-years. To assess the risk of developing subsequent VTE, we performed Cox proportional hazards regression analysis to obtain crude and adjusted hazards ratios (HRs) and 95\% confidence intervals (CIs) between the two cohorts. Cox's regression models were adjusted by age, gender, and all co-morbidities. The Kaplan-Meier method was used to describe the cumulative incidence of VTE among the two groups; differences between the two groups were evaluated using the $\log$ rank test. All data analyzed were performed with SASß(version 9.4; SAS Institute, Inc., Cary, NC, USA). Statistical significance was set at a $p$-value $<0.05$. We applied the Aalen Johansen estimator for analysis of the competing risk of death.

\section{Results}

\subsection{Patient Characteristics}

We included 89,275 participants in this study (NTS group: 17,855; non-NTS group: 71,420). Table 1 reveals that, in the primary analysis, the incidences of co-morbidities were higher in the NTS group than the control group, and we applied regression analysis to adjust for the covariate differences between the two groups. We re-analyzed the data by propensity score matching (PSM) and have provided information on the patients' demographic characteristics, co-morbidities and mortality in the Supplementary Materials (Table S1). 
Table 1. Baseline characteristics of the nontyphoidal salmonellosis (NTS) and non-NTS groups.

\begin{tabular}{|c|c|c|c|}
\hline & \multicolumn{2}{|c|}{ Nontyphoidal Salmonellosis } & \multirow[b]{2}{*}{$p$ Value } \\
\hline & $\begin{array}{c}\text { No } \\
(N=71,420) \\
n(\%)\end{array}$ & $\begin{array}{c}\text { Yes } \\
(N=17,855) \\
n(\%)\end{array}$ & \\
\hline Age, years & & & 1.00 \\
\hline $18-39$ & $18,900(26.5)$ & $4725(26.5)$ & \\
\hline $40-64$ & $26,048(36.5)$ & $6512(36.5)$ & \\
\hline$\geq 65$ & $26,472(37.1)$ & $6618(37.1)$ & \\
\hline Mean $(\mathrm{SD}) *$ & $55.3(19.7)$ & $55.4(19.7)$ & $0.62 *$ \\
\hline Gender & & & 1.00 \\
\hline Female & $32,204(0.45)$ & $8051(0.45)$ & \\
\hline Male & $39,216(0.55)$ & $9804(0.55)$ & \\
\hline Comorbidities & $16,732(23.4)$ & 7951 (44.5) & $<0.001$ \\
\hline Hypertension & $9376(0.13)$ & $4313(0.24)$ & $<0.001$ \\
\hline Diabetes & $4968(0.07)$ & $2854(0.16)$ & $<0.001$ \\
\hline Hyperlipidemia & $2219(0.03)$ & $1224(0.07)$ & $<0.001$ \\
\hline Coronary artery disease & $4465(0.06)$ & $2117(0.12)$ & $<0.001$ \\
\hline Cerebrovascular accident & $4104(0.06)$ & $1664(0.09)$ & $<0.001$ \\
\hline Chronic Kidney disease & $586(0.01)$ & $687(0.04)$ & $<0.001$ \\
\hline Cancer & $2368(0.03)$ & $1977(0.11)$ & $<0.001$ \\
\hline Chronic Obstructive Pulmonary Disease & $2359(0.03)$ & $1453(0.08)$ & $<0.001$ \\
\hline Sleep apnea & $66(0.001)$ & $41(0.002)$ & $<0.001$ \\
\hline Rheumatoid arthritis & $144(0.002)$ & $190(0.01)$ & $<0.001$ \\
\hline Atrial fibrillation & $916(0.01)$ & $537(0.03)$ & $<0.001$ \\
\hline Chronic liver disease & $553(0.01)$ & $419(0.02)$ & 0.75 \\
\hline Pregnancy & $13(0.0002)$ & $2(0.0001)$ & $<0.001$ \\
\hline Lower leg fracture or surgery & $2935(0.04)$ & $1121(0.06)$ & $<0.001$ \\
\hline Mortality & $5560(7.78)$ & $4290(24.0)$ & $<0.001$ \\
\hline
\end{tabular}

Follow-up time: non-NTS group: 4.94 (3.93) years; NTS group: 6.30 (3.67) years. The chi-square test was used to examine categorical data. ${ }^{*} \mathrm{t}$-Test examined continuous data.

\subsection{Risk of DVT and PE}

Table 2 presents the incidence rates and hazard ratios (aHRs) of DVT and PE in the primary analysis (i.e., before PSM). The incidence rate of DVT in the NTS group (12.36 per 10,000 person-years) was higher than among the non-NTS participants (4.77 per 10,000 person-years). PE was more prevalent in the NTS group (6.01 per 10,000 person-years) than in the non-NTS group (2.42 per 10,000 person-years). The NTS group had a 2.35 -fold higher risk of DVT $(95 \% \mathrm{CI}=1.86-2.98)$ and PE by $2.36(95 \% \mathrm{CI}=1.69-3.30)$. We used the Aalen Johansen estimator for the analysis of a competing risk of death. The sub-hazard ratios (SHRs) of DVT and PE were 1.83 (95\% CI $=1.44-2.31$ ) and $1.84(95 \% \mathrm{CI}=1.30-2.60)$, respectively. Compared with subjects aged less than 40 years (the reference age group), those aged over 65 years had the highest risk of developing DVT (aHR $=5.58 ; 95 \% \mathrm{CI}$, 3.38-9.22) and PE (aHR $=4.51 ; 95 \% \mathrm{CI}, 2.46-8.26)$. 
Table 2. Incidence and hazard ratios for deep vein thrombosis (DVT) and pulmonary embolism (PE), comparing patients with and without NTS.

\begin{tabular}{|c|c|c|c|c|c|c|c|c|c|}
\hline \multirow{2}{*}{$\begin{array}{l}\text { Variables } \\
D V T\end{array}$} & \multicolumn{3}{|c|}{ Event } & \multicolumn{2}{|c|}{$\begin{array}{c}\text { Crude HR } \ddagger \\
(95 \% \text { CI })\end{array}$} & \multicolumn{2}{|c|}{$\begin{array}{c}\text { Adjusted HR }{ }^{\S} \\
(95 \% \mathrm{CI})\end{array}$} & \multicolumn{2}{|c|}{$\begin{array}{c}\text { SHR } \\
(95 \% \text { CI })\end{array}$} \\
\hline & & & & & & & & & \\
\hline Non-NTS & 215 & 450,270 & 4.77 & 1.00 & - & 1.00 & - & 1.00 & - \\
\hline NTS & 109 & 88,183 & 12.36 & 2.54 & $(2.02 \text { to } 3.20)^{* * *}$ & 2.35 & (1.86 to 2.98$)^{* * *}$ & 1.83 & $(1.44 \text { to } 2.31)^{* * *}$ \\
\hline \multicolumn{10}{|l|}{ Gender } \\
\hline Female & 154 & 248,049 & 6.21 & 1.00 & - & & & & \\
\hline Male & 170 & 290,404 & 5.85 & 0.94 & (0.75 to 1.17$)$ & & & & \\
\hline \multicolumn{10}{|l|}{ Age } \\
\hline $18-39$ & 22 & 164,576 & 1.34 & 1.00 & - & 1.00 & - & 1.00 & - \\
\hline $40-64$ & 82 & 209,177 & 3.92 & 2.91 & $(1.82 \text { to } 4.66)^{* * *}$ & 2.49 & (1.55 to 4.01$)^{* * *}$ & 2.93 & $(1.47 \text { to } 3.90)^{* * *}$ \\
\hline$\geq 65$ & 220 & 164,700 & 13.36 & 9.68 & $(6.24 \text { to } 15.0)^{* * *}$ & 6.41 & $(4.04 \text { to } 10.2)^{* * *}$ & 5.58 & $(3.38 \text { to } 9.22)^{* * * *}$ \\
\hline \multicolumn{10}{|c|}{ Comorbidities } \\
\hline No & 142 & 432,486 & 3.28 & 1.00 & - & 1.00 & - & 1.00 & - \\
\hline Yes & 182 & 105,967 & 17.18 & 5.06 & $(4.05 \text { to } 6.32)^{* * *}$ & 2.58 & $(2.02 \text { to } 3.29)^{* * *}$ & 2.09 & $(1.60 \text { to } 2.73)^{* * *}$ \\
\hline \multicolumn{10}{|l|}{$P E$} \\
\hline Non-NTS & 109 & 450,270 & 2.42 & 1.00 & - & 1.00 & - & 1.00 & - \\
\hline NTS & 53 & 88,183 & 6.01 & 2.46 & $(1.77 \text { to } 3.41)^{* * *}$ & 2.36 & $(1.69 \text { to } 3.30)^{* * *}$ & 1.84 & $(1.30 \text { to } 2.60)^{* * *}$ \\
\hline \multicolumn{10}{|l|}{ Gender } \\
\hline Female & 76 & 248,049 & 3.06 & 1.00 & - & & & & \\
\hline Male & 86 & 290,404 & 2.96 & 0.96 & (0.71 to 1.31 ) & & & & \\
\hline \multicolumn{10}{|l|}{ Age } \\
\hline $18-39$ & 15 & 164,576 & 0.91 & 1.00 & - & 1.00 & - & 1.00 & - \\
\hline $40-64$ & 43 & 209,177 & 2.06 & 2.28 & $(1.26 \text { to } 4.10)^{* * *}$ & 2.05 & $(1.13$ to 3.71$) *$ & 1.96 & $(1.08$ to 3.56$) *$ \\
\hline$\geq 65$ & 104 & 164,700 & 6.31 & 7.09 & $(4.12 \text { to } 12.2)^{* * *}$ & 5.27 & $(2.97 \text { to } 9.37)^{* * *}$ & 4.51 & $(2.46 \text { to } 8.26)^{* * *}$ \\
\hline \multicolumn{10}{|l|}{ Comorbidities } \\
\hline No & 82 & 432,486 & 1.9 & 1.00 & - & 1.00 & - & 1.00 & - \\
\hline Yes & 80 & 105,967 & 7.55 & 4.09 & $(2.99 \text { to } 5.59)^{* * *}$ & 2.15 & $(1.52 \text { to } 3.03)^{* * *}$ & 1.68 & $(1.15 \text { to } 2.47)^{* *}$ \\
\hline $\begin{array}{l}* p<0.0 \\
\S \text { Adjust } \\
\text { Comorbi } \\
\text { accident, } \\
\text { atrial fibr } \\
\text { group. D }\end{array}$ & IR: a & $\begin{array}{l}1, * * * p \\
\text { sted HI }\end{array}$ & $\begin{array}{l}0.001 . \\
\text { control }\end{array}$ & $\begin{array}{l}\text { Rate, } \\
g \text { for } \\
\text { on, } d\end{array}$ & $\begin{array}{l}\text { idence rate, pe } \\
\text { posure, age, an } \\
\text { etes, hyperlipid }\end{array}$ & $\begin{array}{l}0000 \\
\text { comor } \\
\text { mia, }\end{array}$ & $\begin{array}{l}\text { rson-years. } \ddagger \\
\text { dities. SHR: co } \\
\text { onary artery di } \\
\text { ease, sleep apne } \\
\text { gery were classi } \\
\text { ears. PSM: prop }\end{array}$ & $\begin{array}{l}\text { de H } \\
\text { peting } \\
\text { ase, ce }\end{array}$ & $\begin{array}{l}\text { relative HR. } \\
\text { isk of death; } \\
\text { ebrovascular } \\
\text { toid arthritis, } \\
\text { comorbidity } \\
\text { re matching. }\end{array}$ \\
\hline
\end{tabular}

\subsection{Analysis Stratified by Sex, Age, and Co-Morbidities}

Table 3 demonstrates the associations of risks of VTE by subgroup analyses in terms of sex, age, and co-morbidities. Sex-subgroup analysis revealed that compared with women without NTS, women with NTS had a 2.34-fold higher risk of DVT (95\% CI 1.67-3.28); men with NTS had a 2.26-fold higher risk of DVT than men without NTS (95\% CI 1.63-3.14). Compared with men without NTS, men with NTS had a significantly higher risk of PE (aHR $=3.04,95 \%$ CI 1.94-4.75). In the age subgroup analysis, patients with NTS had an increased association with the risk of DVT and PE in people aged over 65 (for DVT, aHR = 1.68, 95\% CI 1.23-2.30; for PE, aHR = 1.54, 95\% CI 0.96-2.47), and patients with NTS had the highest risk of developing DVT and PE in those aged below 40 (for DVT, aHR $=5.95,95 \% \mathrm{CI}$ 2.22-15.91; for PE, aHR = 6.72, 95\% CI 2.23-20.28) compared with matched non-NTS age subgroups. The $P$-value for interaction between age and exposure of NTS is $<0.001$ for DVT and 0.004 for PE in age subgroup analyses. In the co-morbidities subgroup analysis, in people without mentioned co-morbidities, having a new diagnosis of NTS entailed a significantly higher risk of developing PE than those without NTS. The $p$-value for interaction between co-morbidities and exposure of NTS is $<0.001$ for PE. 
Table 3. Incidence and hazard ratios for DVT and PE among patients stratified by sex, age, and co-morbidities.

\begin{tabular}{|c|c|c|c|c|c|c|c|c|c|c|c|}
\hline \multirow{4}{*}{ Variables } & \multicolumn{6}{|c|}{ Salmonellosis } & \multicolumn{4}{|c|}{ Compared to Control } & \multirow{4}{*}{$\begin{array}{c}p \text { for } \\
\text { Interaction }\end{array}$} \\
\hline & \multirow{2}{*}{\multicolumn{3}{|c|}{$\begin{array}{c}\text { Yes } \\
\text { Events }\end{array}$}} & \multirow{2}{*}{\multicolumn{3}{|c|}{$\begin{array}{c}\text { No } \\
\text { Events }\end{array}$}} & \multirow{3}{*}{\multicolumn{2}{|c|}{$\begin{array}{c}\text { Crude HR } \ddagger \\
(95 \% \text { CI })\end{array}$}} & \multirow{2}{*}{\multicolumn{2}{|c|}{ Adjusted HR ${ }^{\S}$}} & \\
\hline & & & & & & & & & & & \\
\hline & \multirow[t]{2}{*}{$n$} & \multirow[t]{2}{*}{ PY } & \multirow[t]{2}{*}{ Rate $^{+}$} & \multirow[t]{2}{*}{$n$} & \multirow[t]{2}{*}{ PY } & \multirow[t]{2}{*}{ Rate $^{+}$} & & & \multicolumn{2}{|c|}{$(95 \% \mathrm{CI})$} & \\
\hline \multicolumn{6}{|l|}{$D V T$} & & & & & & \\
\hline Gender & & & & & & & & & & & 0.86 \\
\hline Female & 54 & 42,315 & 12.8 & 100 & 205,734 & 4.86 & 2.61 & $(1.87 \text { to } 3.63)^{* * *}$ & 2.34 & $(1.67 \text { to } 3.28)^{* * *}$ & \\
\hline Male & 55 & 45,868 & 12.0 & 115 & 244,536 & 4.70 & 2.48 & $(1.80 \text { to } 3.42)^{* * *}$ & 2.26 & $(1.63 \text { to } 3.14)^{* * *}$ & \\
\hline Age, years & & & & & & & & & & & $<0.001$ \\
\hline $18-39$ & 16 & 30,710 & 5.21 & 6 & 133,866 & 0.45 & 11.4 & $(4.44 \text { to } 29.0)^{* * *}$ & 5.95 & $(2.22 \text { to } 15.9)^{* * *}$ & \\
\hline $40-64$ & 38 & 34,158 & 11.1 & 44 & 175,018 & 2.51 & 4.37 & $(2.83 \text { to } 6.74)^{* * *}$ & 3.40 & $(2.16 \text { to } 5.34)^{* * *}$ & \\
\hline$\geq 65$ & 55 & 23,315 & 23.6 & 165 & 141,385 & 11.67 & 1.99 & $(1.47 \text { to } 2.70)^{* * *}$ & 1.68 & $(1.23 \text { to } 2.30)^{* *}$ & \\
\hline Comorbidity & & & & & & & & & & & 0.54 \\
\hline $\mathrm{NO}$ & 33 & 61,849 & 5.34 & 109 & 370,637 & 2.94 & 1.82 & $(1.24 \text { to } 2.69)^{* * *}$ & 2.33 & $(1.58 \text { to } 3.45)^{* * *}$ & \\
\hline YES & 76 & 26,334 & 28.9 & 106 & 79,633 & 13.3 & 2.10 & $(1.57 \text { to } 2.83)^{* * *}$ & 2.17 & $(1.61 \text { to } 2.93)^{* * *}$ & \\
\hline \multicolumn{7}{|c|}{ Follow-up time, months } & & & & & 0.06 \\
\hline$\leq 2$ & 20 & 103 & 1950 & 2 & 26 & 775 & 0.70 & (0.31 to 1.58$)$ & 0.71 & (0.31 to 1.67$)$ & \\
\hline $3-12$ & 25 & 868 & 288 & 10 & 944 & 106 & 1.25 & (0.72 to 2.19$)$ & 1.42 & (0.79 to 2.56$)$ & \\
\hline$>12$ & 64 & 87,212 & 7.34 & 97 & 449,300 & 2.16 & 1.84 & $(1.38 \text { to } 2.44)^{* * *}$ & 1.75 & $(1.31 \text { to } 2.34)^{* * *}$ & \\
\hline \multicolumn{12}{|l|}{$P E$} \\
\hline Gender & & & & & & & & & & & 0.06 \\
\hline Female & 20 & 42,315 & 4.73 & 56 & 205,734 & 2.72 & 1.73 & $(1.04 \text { to } 2.89)^{* *}$ & 1.65 & (0.98 to 2.77$)$ & \\
\hline Male & 33 & 45,868 & 7.19 & 53 & 244,536 & 2.17 & 3.26 & $(2.11 \text { to } 5.04)^{* * *}$ & 3.04 & $(1.94 \text { to } 4.75)^{* * *}$ & \\
\hline Age, years & & & & & & & & & & & 0.004 \\
\hline 18-39 & 10 & 30,710 & 3.26 & 5 & 133,866 & 0.37 & 8.48 & $(2.90 \text { to } 24.8)^{* * *}$ & 6.72 & $(2.23 \text { to } 20.3)^{* * *}$ & \\
\hline $40-64$ & 20 & 34,158 & 5.86 & 23 & 175,018 & 1.31 & 4.39 & $(2.41 \text { to } 8.00)^{* * *}$ & 3.28 & $(1.75 \text { to } 6.13)^{* * *}$ & \\
\hline$\geq 65$ & 23 & 23,315 & 9.86 & 81 & 141,385 & 5.73 & 1.77 & $(1.11 \text { to } 2.82)^{* *}$ & 1.54 & (0.96 to 2.47$)$ & \\
\hline Comorbidity & & & & & & & & & & & $<0.001$ \\
\hline $\mathrm{NO}$ & 24 & 61,849 & 3.88 & 58 & 370,637 & 1.56 & 2.47 & $(1.54 \text { to } 3.98)^{* * *}$ & 3.05 & $(1.89 \text { to } 4.92)^{* * *}$ & \\
\hline YES & 29 & 26,334 & 11.01 & 51 & 79,633 & 6.40 & 1.70 & $(1.08 \text { to } 2.68)^{* *}$ & 1.74 & $(1.10 \text { to } 2.77)^{*}$ & \\
\hline \multicolumn{7}{|c|}{ Follow-up time, months } & & & & & 0.73 \\
\hline$\leq 2$ & 2 & 103 & 195 & 8 & 26 & 3100 & 1.16 & $(0.25$ to 5.38$)$ & 1.12 & $(0.22$ to 5.73$)$ & \\
\hline $3-12$ & 10 & 868 & 115 & 15 & 944 & 159 & 1.94 & $(0.87$ to 4.33$)$ & 2.41 & $(1.04 \text { to } 5.55)^{*}$ & \\
\hline$>12$ & 97 & 87,212 & 11.1 & 29 & 449,300 & 0.6 & 1.57 & $(1.04$ to 2.37$) *$ & 1.56 & $(1.03 \text { to } 2.38)^{*}$ & \\
\hline
\end{tabular}

\subsection{Sensitivity Analysis}

Table 4 shows that the results were consistent in the two different regression models. We re-analyzed the study by performing PSM to minimize the confounding effects of the mentioned comorbidities on the incidence of VTE. After PSM at a 1:4 ratio, accounting for a competing risk of death, Table S1 shows the baseline comorbidities in both groups, and Table 4 shows that the SHRs of DVT and PE were 1.69 $(95 \% \mathrm{CI}=1.34-2.13)$ and $1.71(95 \% \mathrm{CI}=1.21-2.40)$, respectively. 
Table 4. Cox proportional hazard regression models for risk of DVT and PE in primary and sensitivity analyses.

\begin{tabular}{|c|c|c|c|c|c|c|c|c|c|}
\hline \multirow{2}{*}{ Variable } & \multicolumn{3}{|c|}{ Event } & \multirow{2}{*}{\multicolumn{2}{|c|}{$\begin{array}{c}\text { Crude HR } \ddagger \\
(95 \% \text { CI })\end{array}$}} & \multirow{2}{*}{\multicolumn{2}{|c|}{$\begin{array}{c}\text { Adjusted HR }{ }^{\S} \\
(95 \% \mathrm{CI})\end{array}$}} & \multirow{2}{*}{\multicolumn{2}{|c|}{$\begin{array}{c}\text { SHR } \\
(95 \% \mathrm{CI})\end{array}$}} \\
\hline & $n$ & PY & Rate $^{+}$ & & & & & & \\
\hline \multicolumn{10}{|c|}{ Primary analysis (frequency matching) } \\
\hline \multicolumn{10}{|l|}{$D V T$} \\
\hline non-NTS & 215 & 450,270 & 4.77 & 1.00 & - & 1.00 & - & 1.00 & - \\
\hline NTS & 109 & 88,183 & 12.36 & 2.54 & $(2.02 \text { to } 3.20)^{* * *}$ & 2.35 & $(1.86 \text { to } 2.98)^{* * *}$ & 1.83 & $(1.44 \text { to } 2.31)^{* * *}$ \\
\hline \multicolumn{10}{|l|}{$P E$} \\
\hline non-NTS & 109 & 450,270 & 2.42 & 1.00 & - & 1.00 & - & 1.00 & - \\
\hline NTS & 53 & 88,183 & 6.01 & 2.46 & $(1.77 \text { to } 3.41)^{* * *}$ & 2.36 & $(1.69 \text { to } 3.30)^{* * *}$ & 1.84 & $(1.30 \text { to } 2.60)^{* * *}$ \\
\hline \multicolumn{10}{|c|}{ Sensitivity analysis (PSM) } \\
\hline \multicolumn{10}{|c|}{$D V T$} \\
\hline non-NTS & 256 & 425,265 & 6.02 & 1.00 & - & 1.00 & - & 1.00 & - \\
\hline NTS & 102 & 88,109 & 11.6 & 1.90 & (1.51 to 2.38$)^{* * *}$ & 2.17 & $(1.72 \text { to } 2.73)^{* * * *}$ & 1.69 & $(1.34 \text { to } 2.13)^{* * *}$ \\
\hline \multicolumn{10}{|l|}{$P E$} \\
\hline non-NTS & 113 & 425,265 & 2.66 & 1.00 & - & 1.00 & - & 1.00 & - \\
\hline NTS & 47 & 88,109 & 5.33 & 1.98 & (1.41 to 2.78$)^{* * * *}$ & 2.16 & $(1.53 \text { to } 3.05)^{* * * *}$ & 1.71 & $(1.21 \text { to } 2.40)^{* *}$ \\
\hline
\end{tabular}

\subsection{Time Trends for Risk of DVT and PE}

The incidence rate of DVT and PE in the NTS group demonstrated a time-dependent trend during the follow-up period (Table 3). The risk of DVT in the NTS group, relative to the non-NTS group, was highest after the first 12 months (7.34 per 10,000 years; aHR $=1.75,95 \% \mathrm{CI} 1.31-2.34$ ); the risk of PE was highest between 3 and 12 months (11.1 per 10,000 years; aHR $=1.56,95 \%$ CI 1.03-2.38).

\subsection{Cumulative Incidences Completing Risk Analysis of DVT and PE in NTS and non-NTS Groups}

The Kaplan-Meier graphs (Figure 1(A) and 1(B)) illustrated that the cumulative incidences with death as competing risk for DVT and PE were higher in the NTS group than in the comparison group (log-rank test $p<0.001$ ).

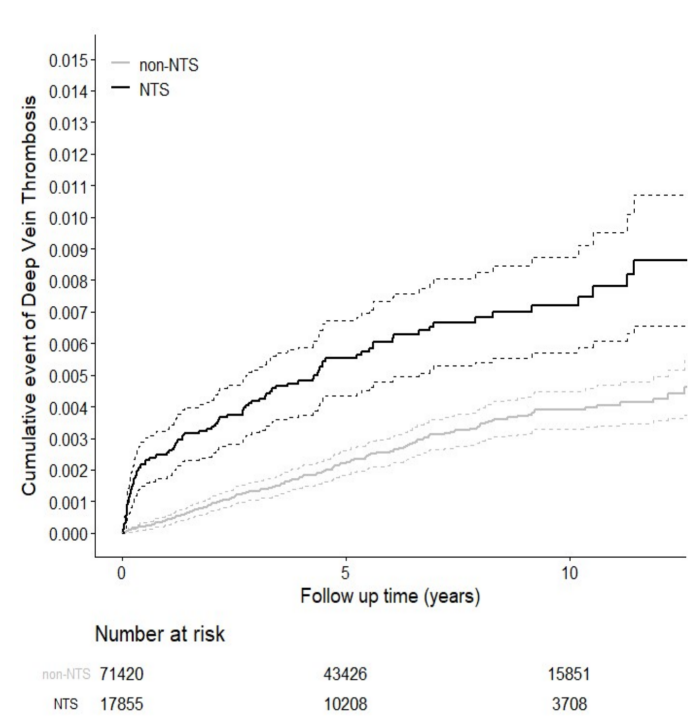

(A)

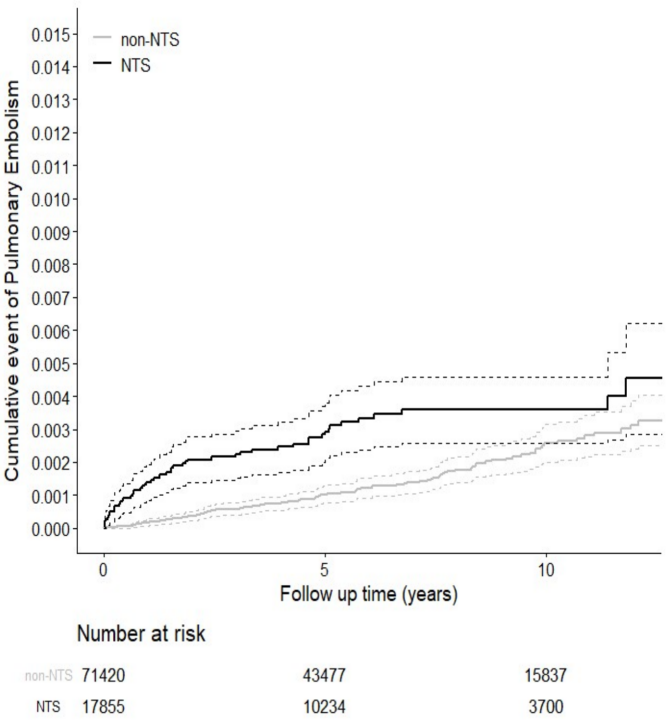

(B)

Figure 1. Cumulative incidence competing risk (death) for deep vein thrombosis (DVT) (A) and pulmonary embolism (PE) (B) among patients with and without NTS. 


\section{Discussion}

This is the first nationwide population-based cohort study to provide epidemiological evidence indicating people with NTS are associated with a higher risk of new-onset DVT (1.83-fold) and PE (1.84-fold) in the Asian population. Patients with a diagnosis of NTS had a significantly higher proportion of comorbidities in comparison with subjects in the non-NTS group. A diagnosis of NTS remained an independent risk factor for subsequent VTE after adjusting for sex, age and co-morbidities. We conducted a re-analysis of our data using PSM that validated these findings. It is notable that males with NTS had a higher risk for PE than females. The study enrolled NTS inpatients as the study population for better disease coding validity. It should be noted, however that as an observation retrospective cohort study, individuals with NTS who never sought medical aid and/or had asymptomatic NTS or mild gastroenteritis were not included in this study. Patients with a discharge diagnosis of NTS have a higher risk of developing DVT and PE in the months following their discharge.

Animal models have shown that bacterial infections-such as Staphylococcus aureus, Klebsiella pneumoniae, and Pseudomonas aeruginosa - are associated with subsequent inflammation and coagulation, and increased platelet aggregation which can last from minutes to hours [12]. A contrast between the Salmonella model of infection-related thrombosis and these other bacterial models is the timing of thrombosis formation-Salmonellae-related thrombosis develops much later. Previous studies indicate that patients with acute infections have an increased risk of VTE [13], especially within the first 2 weeks [14]. Dalager-Pedersen et al. estimated the relationship between VTE and community-acquired bacteremia using a population-based cohort study, and they found the adjusted 90-day odds ratio for VTE to be 1.9 [15]. Mejer et al. indicated a high risk of VTE, as well as an overall hazard ratio from 15.6 within the first month, to 4.5 up to one year following an episode of Staphylococcus aureus bacteraemia [16]. However, epidemiologic evidence regarding NTS and thrombosis risk is lacking. This study determined that people with a history of hospitalization for NTS have a risk of subsequent DVT and PE for a longer period following discharge. The risk and timing of DVT and PE were further analyzed separately, indicating an increased DVT risk at more than 12 months after the index date, with the highest rate of PE occurring in the 3-12 months after the index date. However, we did not investigate the longer-term risk of VTE after NTS, as the study design did not include information about co-morbidities after study entry as time-varying covariates in the Cox models.

The epidemiological causes of increased new-onset VTE in patients with a past history of NTS are unclear. Thromboses are life-threatening complications of systemic infections [17-21]. However, a multicenter prospective study showed that the incidence of VTE remained increased, despite the use of thrombo-prophylaxis in patients with sepsis [22], indicating that the prothrombotic risk is high. Recent studies have attempted to unravel the pathogenesis of NTS-related VTE. Firstly, it has been described that Salmonellae toxins enhance macrophage adhesion and translocation through endothelial cells, promoting phagocytosis of the bacteria into the macrophage-delivering the bacteria into the sub-endothelial space where it may remain in a dormant status for a long period [23]. A recent study has also shown that Salmonella typhimurium can adhere to and penetrate human microvascular endothelial cells by rearrangement of the actin cytoskeleton of host cells, which appears to be encoded by the Salmonella pathogenicity island 1 (SPI-1) locus [24]. Secondly, recent studies have shown that immune cells and the inflammatory process are prothrombotic [25]. Immune-mediated thrombosis has a role in human pathogen defenses; for example, immune cells and specific thrombosis-related molecules forms an intravascular scaffold for containment and destruction of pathogens [26]. Animal studies reveal that aberrant immune-mediated activation of thrombosis may be a key event in the initiation and propagation of DVT [27]. Investigators have described a mouse model of systemic Salmonella typhimurium infection that triggers thrombosis within blood vessels (persisting for weeks) that occurs through the ligation of C-type lectin-like receptor-2 on platelets to podoplanin exposed by damage to the vessel wall [9]. Although such S. typhimurium-mediated thrombosis is not altered by aspirin or clopidegrel [28], the inhibition of podoplanin-CLEC2 interactions with monoclonal antibodies does protect against DVT formation in this animal model [25]. Thirdly, neutrophils, the 
major host defense cells against microbial pathogens, have been recently described to be involved in a process termed "netosis." When stimulated by certain bacteria, neutrophils release neutrophil extracellular traps (NETs) [29]—comprised of negatively charged neutrophil DNA backbones decorated with antimicrobial factors such as elastase, cathepsin G, and proteinase 3-that are capable of cleaving the virulence factors of Shigella flexneri, Salmonella typhimurium, and other pathogens [29-31]. Salmonella typhimurium has been shown to stimulate NETs that consequently trap and eliminate Salmonellae via granular proteins and H2A histone [30]. However, uncontrolled netosis may lead to extensive thromboses and is associated with subsequent ischemia [31,32]. Interestingly, several studies showed that neutrophils in older individuals generally "cast" fewer NETs [33,34]. Interestingly we observe that NTS has a higher association with subsequent VTE in younger patients, aged $<40$ years, who may have a stronger immune response (DVT, aHR $=5.95,95 \% \mathrm{CI} 2.22-15.91 ; \mathrm{PE}, \mathrm{aHR}=6.72,95 \% \mathrm{CI}$ 2.23-20.28 when compared to control patients of the same age).

Several limitations of this study should be mentioned. First, NHIRD does not provide detailed demographics such as lifestyle information, tobacco consumption, body mass index, physical activity, or diet habits. Second, the hospitalization claim dataset from NHIRD does not include laboratory reports, indications of disease severity, and drug information, such as the use of anti-contraceptive drugs or antibiotics. Finally, a retrospective cohort study design is subject to biases due to unknown confounders. However, by analyzing these data using multivariable models and a sensitivity analysis, we have attempted to attenuate potential biases from unmeasured associated confounders.

\section{Conclusions}

In this population-based retrospective cohort study, NTS was associated with an increased risk of new-onset DVT and PE. Notably, the highest increase in relative risk of VTE occurs in younger patients (18-39 years) where the absolute risk of VTE is low. Nonetheless, clinicians should be aware that patients with a history of hospitalization with NTS are at increased risk for VTE within the first year following discharge, especially in situations where other VTE risk factors are present (e.g., post-operative, during prolonged immobility, pregnancy, etc.).

Supplementary Materials: The following are available online at http://www.mdpi.com/1660-4601/17/10/3567/s1, Table S1: Comparison of demographics and comorbidity between individuals with and without nontyphoidal salmonellosis in propensity score matched cohort.

Author Contributions: Conceptualization, D.-K.W., R.C., J.C.-C.W., H.-T.Y., Y.-M.H., and C.-H.H.; acquisition of data, H.-T.Y.; analysis and interpretation of data, D.-K.W., R.C., J.C.-C.W., H.-T.Y., Y.-M.H., and C.-H.H.; writing—original draft preparation, D.-K.W., R.C., and Y.-M.H.; writing-review and editing, J.C.-C.W., Y.-M.H., and C.-H.H. All authors have read and agreed to the published version of the manuscript.

Funding: This study is supported in part by the Taiwan Ministry of Health and Welfare Clinical Trial Center (MOHW108-TDU-B-212-133004), China Medical University Hospital, the Academia Sinica Stroke Biosignature Project (BM10701010021), the MOST Clinical Trial Consortium for Stroke (MOST 108-2321-B-039-003-), the Tseng-Lien Lin Foundation, Taichung, Taiwan, and Katsuzo and Kiyo Aoshima Memorial Funds, Japan.

Conflicts of Interest: The authors declare that there is no conflict of interest.

\section{References}

1. Gromadzinski, L.; Targonski, R.; Januszko-Giergielewicz, B.; Ciurzynski, M.; Pruszczyk, P. The influence of acute pulmonary embolism on early and delayed prognosis for patients with chronic heart failure. Cardiol. J. 2012, 19, 625-631. [CrossRef] [PubMed]

2. Wolberg, A.S.; Rosendaal, F.R.; Weitz, J.I.; Jaffer, I.H.; Agnelli, G.; Baglin, T.; Mackman, N. Venous thrombosis. Nat. Rev. Dis. Primers 2015, 1, 15006. [CrossRef] [PubMed]

3. Schmidt, M.; Horvath-Puho, E.; Thomsen, R.W.; Smeeth, L.; Sorensen, H.T. Acute infections and venous thromboembolism. J. Intern. Med. 2012, 271, 608-618. [CrossRef] [PubMed] 
4. Mejer, N.; Westh, H.; Schonheyder, H.C.; Jensen, A.G.; Larsen, A.R.; Skov, R.; Benfield, T.; Danish Staphylococcal Bacteraemia Study Group. Increased risk of venous thromboembolism within the first year after staphylococcus aureus bacteraemia: A nationwide observational matched cohort study. J. Intern. Med. 2014, 275, 387-397. [CrossRef] [PubMed]

5. Carey, J.; Buchstein, S.; Shah, S. Septic deep vein thrombosis due to salmonella johannesburg. J. Infect. 2001, 42, 79-80. [CrossRef] [PubMed]

6. Salamon, S.A.; Prag, J. A case of superficial septic thrombophlebitis in a varicose vein caused by salmonella panama. Clin. Microbiol. Infect. 2001, 7, 34-36. [CrossRef]

7. Schifferdecker, B.; Merchan, J.A.; Ahmar, C.; Worthington, M.; Griben, A.; Schainfeld, R.M.; Soukas, P.A. Endovascular treatment of septic thrombophlebitis: A case report of a rare complication and review of the literature. Vasc. Med. 2009, 14, 47-50. [CrossRef]

8. Wright, A.E.; Knapp, H.H. A note on the causation and treatment of thrombosis occurring in connection with typhoid fever. Med. Chir. Trans. 1903, 86, 1-19.

9. Hitchcock, J.R.; Cook, C.N.; Bobat, S.; Ross, E.A.; Flores-Langarica, A.; Lowe, K.L.; Khan, M.; Dominguez-Medina, C.C.; Lax, S.; Carvalho-Gaspar, M.; et al. Inflammation drives thrombosis after salmonella infection via clec-2 on platelets. J. Clin. Investig. 2015, 125, 4429-4446. [CrossRef]

10. Stapels, D.A.C.; Hill, P.W.S.; Westermann, A.J.; Fisher, R.A.; Thurston, T.L.; Saliba, A.E.; Blommestein, I.; Vogel, J.; Helaine, S. Salmonella persisters undermine host immune defenses during antibiotic treatment. Science 2018, 362, 1156-1160. [CrossRef]

11. Wu, H.H.; Chen, Y.T.; Shih, C.J.; Lee, Y.T.; Kuo, S.C.; Chen, T.L. Association between recent use of proton pump inhibitors and nontyphoid salmonellosis: A nested case-control study. Clin. Infect. Dis. 2014, 59, 1554-1558. [CrossRef] [PubMed]

12. Surewaard, B.G.J.; Thanabalasuriar, A.; Zeng, Z.; Tkaczyk, C.; Cohen, T.S.; Bardoel, B.W.; Jorch, S.K.; Deppermann, C.; Bubeck Wardenburg, J.; Davis, R.P.; et al. Alpha-toxin induces platelet aggregation and liver injury during staphylococcus aureus sepsis. Cell Host Microbe 2018, 24, 271-284.e3. [CrossRef] [PubMed]

13. Gardlund, B. Fatal pulmonary embolism in hospitalized non-surgical patients. Acta Med. Scand. 1985, 218, 417-421. [CrossRef] [PubMed]

14. Belch, J.J.; Lowe, G.D.; Ward, A.G.; Forbes, C.D.; Prentice, C.R. Prevention of deep vein thrombosis in medical patients by low-dose heparin. Scott. Med. J. 1981, 26, 115-117. [CrossRef] [PubMed]

15. Gardlund, B. Randomised, controlled trial of low-dose heparin for prevention of fatal pulmonary embolism in patients with infectious diseases. The heparin prophylaxis study group. Lancet 1996, 347, 1357-1361.

16. Alikhan, R.; Cohen, A.T.; Combe, S.; Samama, M.M.; Desjardins, L.; Eldor, A.; Janbon, C.; Leizorovicz, A.; Olsson, C.G.; Turpie, A.G. Prevention of venous thromboembolism in medical patients with enoxaparin: A subgroup analysis of the medenox study. Blood Coagul. Fibrinolysis 2003, 14, 341-346. [CrossRef]

17. Cohen, A.T.; Davidson, B.L.; Gallus, A.S.; Lassen, M.R.; Prins, M.H.; Tomkowski, W.; Turpie, A.G.; Egberts, J.F.; Lensing, A.W.; Investigators, A. Efficacy and safety of fondaparinux for the prevention of venous thromboembolism in older acute medical patients: Randomised placebo controlled trial. BMJ 2006, 332, 325-329. [CrossRef]

18. Kaplan, D.; Casper, T.C.; Elliott, C.G.; Men, S.; Pendleton, R.C.; Kraiss, L.W.; Weyrich, A.S.; Grissom, C.K.; Zimmerman, G.A.; Rondina, M.T. Vte incidence and risk factors in patients with severe sepsis and septic shock. Chest 2015, 148, 1224-1230. [CrossRef]

19. Ohl, M.E.; Miller, S.I. Salmonella: A model for bacterial pathogenesis. Annu. Rev. Med. 2001, 52, $259-274$. [CrossRef]

20. Van Sorge, N.M.; Zialcita, P.A.; Browne, S.H.; Quach, D.; Guiney, D.G.; Doran, K.S. Penetration and activation of brain endothelium by salmonella enterica serovar typhimurium. J. Infect. Dis. 2011, 203, 401-405. [CrossRef]

21. Riegger, J.; Byrne, R.A.; Joner, M.; Chandraratne, S.; Gershlick, A.H.; Ten Berg, J.M.; Adriaenssens, T.; Guagliumi, G.; Godschalk, T.C.; Neumann, F.J.; et al. Histopathological evaluation of thrombus in patients presenting with stent thrombosis. A multicenter european study: A report of the prevention of late stent thrombosis by an interdisciplinary global european effort consortium. Eur. Heart J. 2016, 37, 1538-1549. [CrossRef] [PubMed]

22. Engelmann, B.; Massberg, S. Thrombosis as an intravascular effector of innate immunity. Nat. Rev. Immunol. 2013, 13, 34-45. [CrossRef] [PubMed] 
23. Von Bruhl, M.L.; Stark, K.; Steinhart, A.; Chandraratne, S.; Konrad, I.; Lorenz, M.; Khandoga, A.; Tirniceriu, A.; Coletti, R.; Kollnberger, M.; et al. Monocytes, neutrophils, and platelets cooperate to initiate and propagate venous thrombosis in mice in vivo. J. Exp. Med. 2012, 209, 819-835. [CrossRef] [PubMed]

24. Zarychanski, R.; Abou-Setta, A.M.; Kanji, S.; Turgeon, A.F.; Kumar, A.; Houston, D.S.; Rimmer, E.; Houston, B.L.; McIntyre, L.; Fox-Robichaud, A.E.; et al. The efficacy and safety of heparin in patients with sepsis: A systematic review and metaanalysis. Crit. Care Med. 2015, 43, 511-518. [CrossRef]

25. Payne, H.; Ponomaryov, T.; Watson, S.P.; Brill, A. Mice with a deficiency in clec-2 are protected against deep vein thrombosis. Blood 2017, 129, 2013-2020. [CrossRef]

26. Budnik, I.; Brill, A. Immune factors in deep vein thrombosis initiation. Trends Immunol. 2018, 39, 610-623. [CrossRef]

27. Brinkmann, V.; Reichard, U.; Goosmann, C.; Fauler, B.; Uhlemann, Y.; Weiss, D.S.; Weinrauch, Y.; Zychlinsky, A. Neutrophil extracellular traps kill bacteria. Science 2004, 303, 1532-1535. [CrossRef]

28. Brinkmann, V.; Zychlinsky, A. Beneficial suicide: Why neutrophils die to make nets. Nat. Rev. Microbiol. 2007, 5, 577-582. [CrossRef]

29. Averhoff, P.; Kolbe, M.; Zychlinsky, A.; Weinrauch, Y. Single residue determines the specificity of neutrophil elastase for shigella virulence factors. J. Mol. Biol. 2008, 377, 1053-1066. [CrossRef]

30. Fuchs, T.A.; Brill, A.; Wagner, D.D. Neutrophil extracellular trap (net) impact on deep vein thrombosis. Arterioscler. Thromb. Vasc. Biol. 2012, 32, 1777-1783. [CrossRef]

31. Yang, H.; Biermann, M.H.; Brauner, J.M.; Liu, Y.; Zhao, Y.; Herrmann, M. New insights into neutrophil extracellular traps: Mechanisms of formation and role in inflammation. Front. Immunol. 2016, 7, 302. [CrossRef] [PubMed]

32. Kimball, A.S.; Obi, A.T.; Diaz, J.A.; Henke, P.K. The emerging role of nets in venous thrombosis and immunothrombosis. Front. Immunol. 2016, 7, 236. [CrossRef] [PubMed]

33. Hazeldine, J.; Harris, P.; Chapple, I.L.; Grant, M.; Greenwood, H.; Livesey, A.; Sapey, E.; Lord, J.M. Impaired neutrophil extracellular trap formation: A novel defect in the innate immune system of aged individuals. Aging Cell 2014, 13, 690-698. [CrossRef] [PubMed]

34. Itagaki, K.; Kaczmarek, E.; Lee, Y.T.; Tang, I.T.; Isal, B.; Adibnia, Y.; Sandler, N.; Grimm, M.J.; Segal, B.H.; Otterbein, L.E.; et al. Mitochondrial DNA released by trauma induces neutrophil extracellular traps. PLoS ONE 2015, 10, e0120549. [CrossRef] 